\title{
Evaluation of water content in honey using microwave transmission line technique
}

DOI:

10.1016/j.jfoodeng.2017.07.009

\section{Document Version}

Accepted author manuscript

Link to publication record in Manchester Research Explorer

\section{Citation for published version (APA):}

Li, Z., Haigh, A., Soutis, C., Gibson, A., \& Sloan, R. (2017). Evaluation of water content in honey using microwave transmission line technique. Journal of Food Engineering. https://doi.org/10.1016/j.jfoodeng.2017.07.009

\section{Published in:}

Journal of Food Engineering

\section{Citing this paper}

Please note that where the full-text provided on Manchester Research Explorer is the Author Accepted Manuscript or Proof version this may differ from the final Published version. If citing, it is advised that you check and use the publisher's definitive version.

\section{General rights}

Copyright and moral rights for the publications made accessible in the Research Explorer are retained by the authors and/or other copyright owners and it is a condition of accessing publications that users recognise and abide by the legal requirements associated with these rights.

\section{Takedown policy}

If you believe that this document breaches copyright please refer to the University of Manchester's Takedown Procedures [http://man.ac.uk/04Y6Bo] or contact uml.scholarlycommunications@manchester.ac.uk providing relevant details, so we can investigate your claim.

\section{OPEN ACCESS}


Evaluation of added water content in honey using microwave transmission line technique Zhen $\mathrm{Li}^{1}$, Arthur Haigh ${ }^{2}$, Constantinos Soutis ${ }^{1,3 *}$, Andrew Gibson ${ }^{3,4}$ and Robin Sloan ${ }^{2}$ ${ }^{1}$ Aerospace Research Institute, The University of Manchester, Manchester, M13 9PL, UK ${ }^{2}$ School of Electrical and Electronic Engineering, The University of Manchester, Manchester, M13 9PL, UK

${ }^{3}$ School of Mechanical, Aerospace and Civil Engineering, The University of Manchester, Manchester, M13 9PL, UK

${ }^{4}$ Faculty of Science and Engineering, Manchester Metropolitan University, Manchester, M1 5GD, UK

*Corresponding author: constantinos.soutis@manchester.ac.uk

\begin{abstract}
The microwave transmission line technique is presented as an effective method for evaluation of honey purity for the first time. The electrical permittivity is an intrinsic parameter of a material that can be used as a purity index. For the permittivity calculation, it is found that the combination of the characteristic matrix method and Tischer's model can offer the highest accuracy. A genetic algorithm is introduced to provide an initial approximate permittivity value and acquire the Cole-Cole parameters of the honeys. The accuracy provided by the methodology used in this study is superior to that offered by a commercially available probe. Operating at room temperature and a frequency range of 6-8 GHz, the measurements demonstrate that the permittivity of honey increases with increased added water. A relationship between the added water content and the permittivity of honey-water mixture is established, which could be a powerful tool for detecting honey adulteration.
\end{abstract}

Keywords: honey, transmission line technique, permittivity, added water content, adulteration 


\section{Introduction}

The average composition of honey is about $80 \%$ carbohydrates (e.g., fructose and glucose), $18 \%$ water and $2 \%$ amino acids, minerals, vitamins and proteins. It has been used as a high nutritional food or as a remedy for many diseases. For these benefits to materialise, honey should be free from water and other sweeteners (National Honey Board, 2003). However, for economic gain, honey has become a target of excessive adulteration worldwide. For example, water is one of the common ingredients for honey adulteration. The adulteration is both fraudulent and unfair to consumers, and it could cause health concerns to those who rely on nutrients from honey products. Therefore, determination of the purity of honey is important for manufacturers, retailers, consumers and regulatory authorities (Chen et al., 2011).

Two types of methods are commonly used for honey quality assessment: sensory and chemical analyses (e.g., liquid chromatography, infrared spectroscopy and mass spectrometry). The sensory analysis mainly detects honey colour, viscosity, smell, flavour and crystallisation. However, the accuracy of the sensory analysis is limited and usually depends on the experience of the sensory panellists. Chemical analysis also has some disadvantages, such as need for highly skilled labour, ultrapure preparation, expensive instruments and large instrumental analysis (Bázár et al., 2016). Thus, the development of a relatively fast, easy-to-use and low-cost measurement method becomes attractive.

A microwave-based technique can be an alternative method for quality assessment on the basis of the electrical permittivity, which is an intrinsic parameter of a material that represents the interaction with the electromagnetic field. Establishing explicit relationships between the permittivity and the agri-food constituents can provide a means of rapid inspection of properties (e.g., moisture, fat and salt content) (Chua et al., 2007; Gibson et al., 2008). Microwave detection methods have various attributes, such as fast (few minutes rather than hours), non-hazardous, capable of measuring bulk properties and less sensitive to environmental conditions (Kharkovsky and Zoughi, 2007; Li et al., 
2017). A number of microwave techniques have been reported in the literature and used in practice for liquids: open-ended rectangular waveguide (Karpisz et al., 2016)/ coaxial probe (Guo et al., 2010) techniques, time domain spectroscopy/ reflectometry (TDR) method (Puranik et al., 1991), resonance methods (e.g., resonant cavity(Liao et al., 2001) and coupled split-ring resonator (Watts et al., 2016)) and free space methods (Jose et al., 2001). Each method has its own particular advantages, disadvantages and applications. Specifically, the open-ended methods are prone to errors introduced by improper contact between the probe and the material surface (e.g., air gaps or air bubbles). The TDR measuring instruments are expensive (Venkatesh and Raghavan, 2005). The resonance approach is inherently narrowband and requires careful sample preparation and calibration (Kraszewski and Nelson, 1992). For the free space technique, special attention must be paid to the choice of horn antennae, design of the sample holder and the sample geometry and location. On the other hand, the transmission line technique is robust, broadband and suited to materials with a wide range of dielectric loss. For the liquid measurement, two waveguide cells with window can be made to hold the sample on each side. However, few studies have been made on the measurement of honey using this technique.

In this work, the transmission line technique is adopted for the study of honeys and honey adulteration for the first time. First, the Cole-Cole equation for the description of dielectric properties of liquids is introduced. Then the liquid permittivity measurement and the available methods for the permittivity calculation are addressed. From the measurement of distilled water at room temperature over two frequency bands (i.e., 6-8 GHz and 8-12 GHz), the efficiency and accuracy of each permittivity calculation method and frequency band are evaluated by comparison with the empirical data provided by the Cole-Cole equation. Afterwards, the measurements of two types of honeys are conducted over 6-8 GHz. A genetic algorithm, an optimisation method, is employed to quickly search the possible permittivity of the honey samples, which will be a starting point for further accurate calculation. It is also used to obtain the Cole-Cole dielectric parameters for clear and set 
honeys. The effect of the calibration errors on the accuracy of the permittivity measurement is studied. In addition, its accuracy is compared with that by a by a commercially available dielectric probe. Finally, the effect of the added water on the permittivity of honey-water mixture is investigated in detail and a purity index is identified.

\section{Dielectric properties of liquids}

\subsection{Definition of permittivity}

When microwave energy is directed towards a material, part of the energy is reflected, part is transmitted and part is absorbed by the sample. The portion of energy that falls into these three categories have been defined in terms of the scattering parameters and these can be related to the dielectric properties of the sample (Gibson et al., 2008). The fundamental electrical properties through which the interactions between the electromagnetic wave and the material are described is the complex permittivity $\varepsilon$. It is mathematically expressed as:

$$
\varepsilon=\varepsilon_{0} \varepsilon_{r}=\varepsilon_{0}\left(\varepsilon_{r}^{\prime}-j \varepsilon_{r}^{\prime \prime}\right)
$$

where $\varepsilon_{0}=8.8542 \times 10^{-12} \mathrm{~F} / \mathrm{m}$ is the permittivity of free space, and $\varepsilon_{r}$ is the relative permittivity. The real part $\varepsilon_{r}^{\prime}$ of $\varepsilon_{r}$, or dielectric constant, characterises the ability of a material or a substance to store the electric field energy. $\varepsilon^{\prime \prime}{ }_{r}$ (positive), or dielectric loss factor, reflects the ability of a material to dissipate the electric energy in the form of heat.

\subsection{Cole-Cole equation for description of liquids}

The Cole-Cole equation is a relaxation model that is often used to describe the relative permittivity of liquids. It is given by the equation:

$$
\varepsilon_{r}=\frac{\varepsilon_{s}-\varepsilon_{\infty}}{1+(j \omega \tau)^{1-\alpha}}+\varepsilon_{\infty}
$$

where $\varepsilon_{\mathrm{s}}$ and $\varepsilon_{\infty}$ are the 'static' and 'infinite frequency' permittivity. $\omega$ is the angular frequency and $\tau$ is a time constant. The exponent parameter $\alpha$ is a value between 0 and 1 . 
For water, the static frequency constant $\varepsilon_{\mathrm{s}}$ is described by (Hasted, 1973)

$$
\varepsilon_{s}=87.740-0.40008 \mathrm{~T}+9.398 \times 10^{-4} \mathrm{~T}^{2}-1.410 \times 10^{-6} \mathrm{~T}^{3}
$$

where $\mathrm{T}$ is the temperature in ${ }^{\circ} \mathrm{C}$.

And the other relaxation parameters $\varepsilon_{\infty}, \tau$ and $\alpha$ for water are listed in Table 1.

Table 1 Water relaxation parameters derived from the Cole-Cole equation (Hasted, 1973)

\begin{tabular}{cccccccc}
\hline $\mathrm{T}\left({ }^{\circ} \mathrm{C}\right)$ & 0 & 10 & 20 & 30 & 40 & 50 & 60 \\
\hline$\varepsilon_{\infty}$ & $4.46 \pm 0.17$ & $4.10 \pm 0.15$ & $4.23 \pm 0.16$ & $4.20 \pm 0.16$ & $4.16 \pm 0.15$ & $4.13 \pm 0.15$ & $4.21 \pm 0.16$ \\
$\tau\left(10^{-11} \mathrm{~s}\right)$ & 1.79 & 1.26 & 0.93 & 0.72 & 0.58 & 0.48 & 0.39 \\
$\alpha$ & 0.014 & 0.014 & 0.013 & 0.012 & 0.009 & 0.013 & 0.011
\end{tabular}

The variation of the relative permittivity of water with respect to frequency and temperature over 1-20 GHz is plotted in Figure 1. In this frequency range, $\varepsilon_{\mathrm{r}}^{\prime}$ and $\varepsilon^{\prime \prime}$ are of the same order of magnitude, which demonstrates the high-loss characteristic of water.

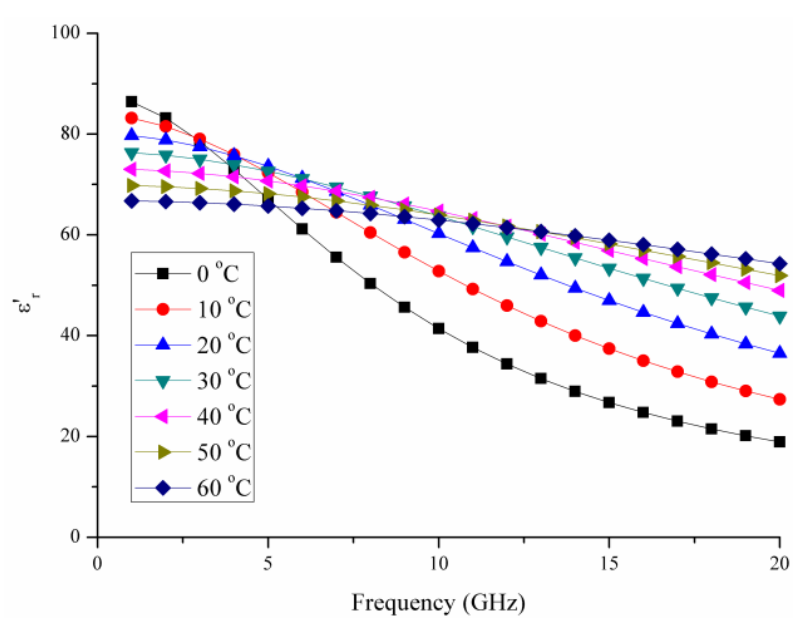

(a) $\varepsilon_{r}^{\prime}$

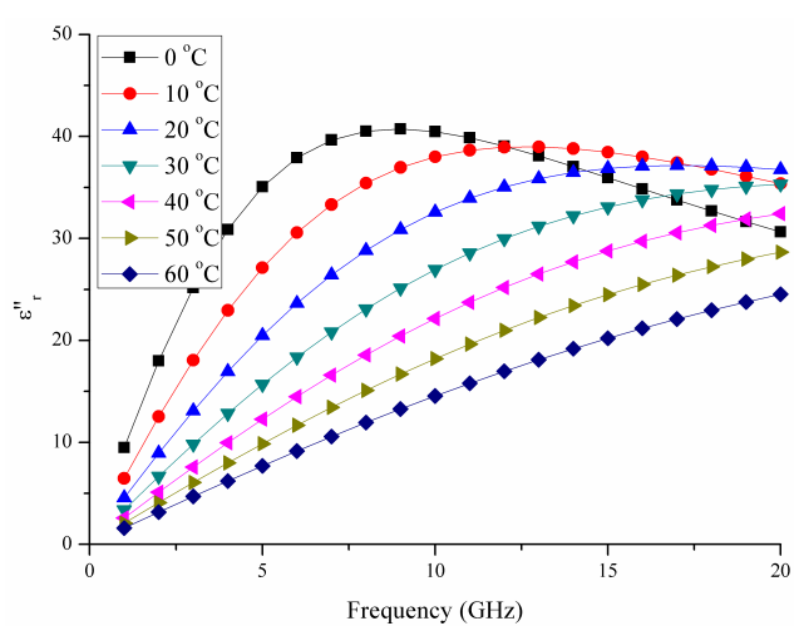

(b) $\varepsilon^{\prime \prime}{ }_{r}$

Figure 1 Variation of the relative permittivity of distilled water

with respect to frequency at various temperatures

\subsection{Penetration depth of microwaves into dielectrics}

Considering the effect of the lossy medium, the power of the microwaves decays exponentially through the thickness. The penetration depth $d_{p}$ is a practical parameter used for the evaluation of 
signal propagation. It is defined as the depth where the microwave power is reduced to 1/e (about 37 $\%)$ below the surface. For a dielectric material, $d_{p}$ can be calculated by (Pozar, 2011):

$$
d_{p}=\frac{c_{0}}{\sqrt{2} \pi f\left\{\varepsilon_{r}^{\prime}\left[\sqrt{1+\left(\varepsilon_{r}^{\prime \prime} / \varepsilon_{r}^{\prime}\right)^{2}}-1\right]\right\}^{1 / 2}}
$$

where $f$ is the operating frequency, and $c_{0}$ is the speed of light in free space. It is seen that the penetration depth is inversely proportional to the frequency.

\section{Three-layer problem of the liquid permittivity measurement}

The microwave transmission line technique is used with a three-layer arrangement. The schematic diagram of the in-waveguide measurement is illustrated in Figure 2, where two waveguide flanges with window (i.e., Layer 1 and Layer 3) provide a liquid-tight enclosure for

the liquid (i.e., Layer 2). Lengths of Layer 1, Layer 2 and Layer 3 are $t_{1}, t_{2}$ and $t_{3}$, respectively. The relative permittivity of Layer 1, Layer 2 and Layer 3 are $\varepsilon_{\mathrm{r} 1}, \varepsilon_{\mathrm{r} 2}$ and $\varepsilon_{\mathrm{r} 3}$, respectively. And the relative permeability of Layer 1, Layer 2 and Layer 3 are $\mu_{\mathrm{r} 1}, \mu_{\mathrm{r} 2}$ and $\mu_{\mathrm{r} 3}$ respectively. Common dielectric materials are non-magnetic and their relative permeability is very close to one. Hence, the permittivity is the parameter of interest in this work.

All four scattering (S) parameters (i.e., $\mathrm{S}_{11}, \mathrm{~S}_{12}, \mathrm{~S}_{21}$ and $\mathrm{S}_{22}$ ) are obtained at the two reference planes after calibration. The measurement system is operated in the dominant $\mathrm{TE}_{10}$ mode, where only one propagation mode exists in the frequency band of operation. Two different methods are employed for permittivity calculation of the unknown liquid layer: characteristic matrix $(\mathrm{CM})$ method (Baginski et al., 2005; Rulf, 1988) and Musil-Zacek approach (Musil and Zacek, 1986). 


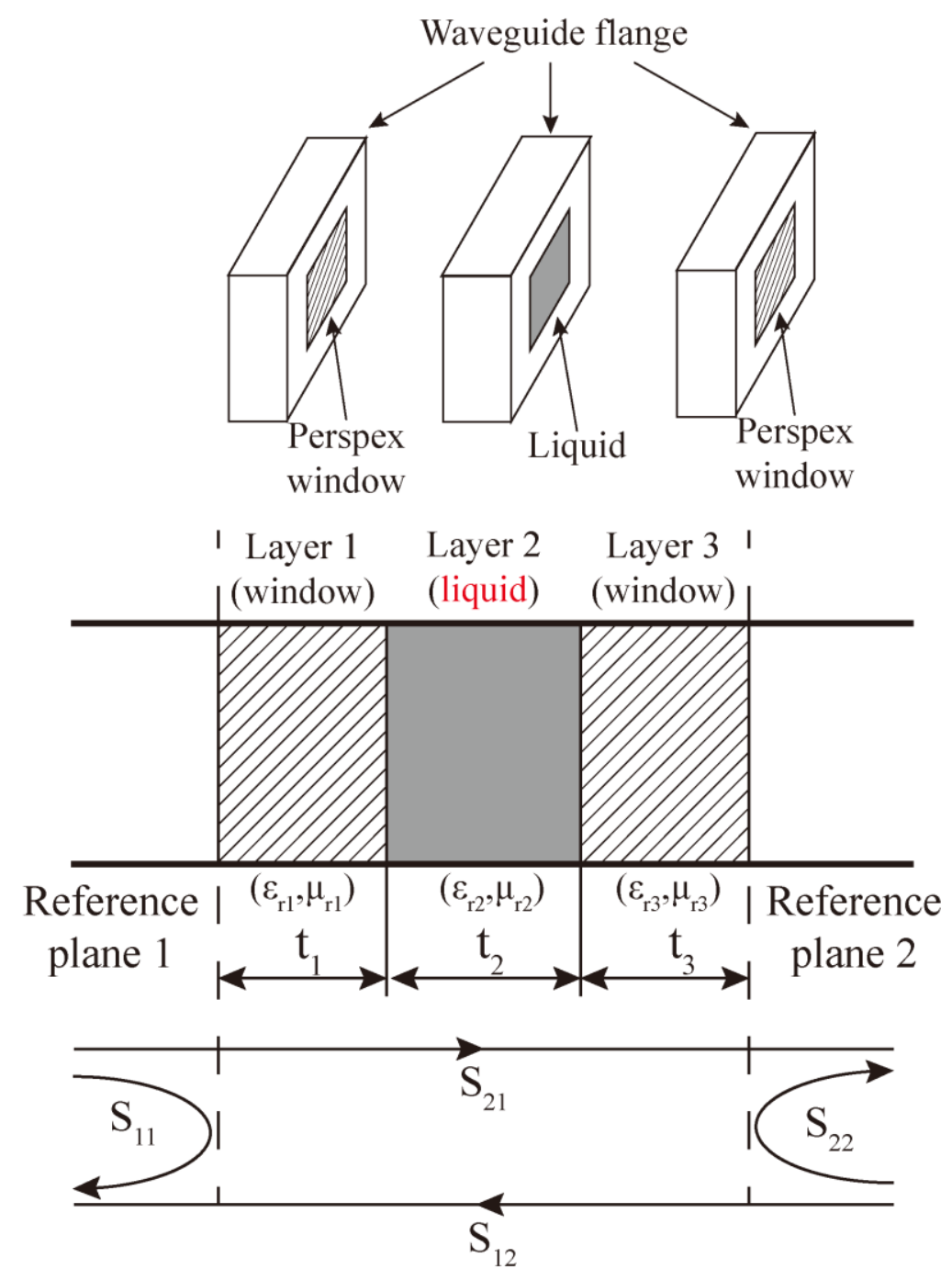

Figure 2 Three-layer problem of the liquid permittivity measurement using the transmission line technique

\section{Permittivity calculation}

\subsection{Characteristic matrix method}

For this multi-layer problem, it is convenient to use the characteristic (or ABCD) matrix method. The ABCD matrix of the cascade network can be readily obtained by multiplying the ABCD matrices of the individual layer. By de-embedding, the ABCD matrix of the unknown sample layer can be computed. Subsequently, the S parameters for the sample layer that are functions of the permittivity can be converted from the ABCD matrix. 
First, the measured S parameters for all the three layers are converted to ABCD parameters using the following equations:

$$
\begin{aligned}
& \mathrm{A}=\frac{\left(1+\mathrm{S}_{11}\right)\left(1-\mathrm{S}_{22}\right)+\mathrm{S}_{12} \mathrm{~S}_{21}}{2 \mathrm{~S}_{21}} \\
& \mathrm{~B}=\mathrm{Z}_{0} \frac{\left(1+\mathrm{S}_{11}\right)\left(1+\mathrm{S}_{22}\right)-\mathrm{S}_{12} \mathrm{~S}_{21}}{2 \mathrm{~S}_{21}} \\
& \mathrm{C}=\frac{1}{Z_{0}} \frac{\left(1-\mathrm{S}_{11}\right)\left(1-\mathrm{S}_{22}\right)-\mathrm{S}_{12} \mathrm{~S}_{21}}{2 \mathrm{~S}_{21}} \\
& \mathrm{D}=\frac{\left(1-\mathrm{S}_{11}\right)\left(1+\mathrm{S}_{22}\right)+\mathrm{S}_{12} \mathrm{~S}_{21}}{2 \mathrm{~S}_{21}}
\end{aligned}
$$

where $\mathrm{Z}_{0}$ is the empty waveguide impedance.

This overall $\mathrm{ABCD}$ is the product of the $\mathrm{ABCD}$ matrices representing each layer (Baginski et al., 2005):

$$
\begin{aligned}
& {\left[\begin{array}{ll}
A & B \\
C & D
\end{array}\right]=\left[\begin{array}{ll}
A_{1} & B_{1} \\
C_{1} & D_{1}
\end{array}\right]\left[\begin{array}{cc}
A_{2} & B_{2} \\
C_{2} & D_{2}
\end{array}\right]\left[\begin{array}{cc}
A_{3} & B_{3} \\
C_{3} & D_{3}
\end{array}\right]} \\
& {\left[\begin{array}{cc}
A_{\mathrm{n}} & B_{\mathrm{n}} \\
C_{\mathrm{n}} & D_{\mathrm{n}}
\end{array}\right]=\left[\begin{array}{cc}
\cosh \left(\gamma_{\mathrm{n}} t_{\mathrm{n}}\right) & Z_{\mathrm{n}} \sinh \left(\gamma_{\mathrm{n}} t_{\mathrm{n}}\right) \\
\sinh \left(\gamma_{\mathrm{n}} t_{\mathrm{n}}\right) / Z_{\mathrm{n}} & \cosh \left(\gamma_{\mathrm{n}} t_{\mathrm{n}}\right)
\end{array}\right](\mathrm{n}=1,3)}
\end{aligned}
$$

where $\gamma_{\mathrm{n}}$ and $\mathrm{Z}_{\mathrm{n}}$ are the wave propagation constant and wave impedance of the $\mathrm{nth}$ layer, respectively, and given by

$$
\begin{gathered}
\gamma_{n}=j 2 \pi \sqrt{\frac{\varepsilon_{\mathrm{rn}} \mu_{\mathrm{rn}}}{\lambda^{2}}-\frac{1}{\lambda_{c}^{2}}} \\
Z_{n}=\frac{j 2 \pi \mu_{\mathrm{rn}}}{\lambda_{g} \gamma_{n}}
\end{gathered}
$$


where $\lambda$ and $\lambda_{\mathrm{c}}$ are the free space and cut-off wavelengths, respectively, while $\lambda_{\mathrm{g}}$ is the guide wavelength of the empty waveguide:

$$
\lambda_{g}=\frac{1}{\sqrt{\frac{1}{\lambda^{2}}-\frac{1}{\lambda_{c}^{2}}}}=\frac{\lambda}{\sqrt{1-\left(\frac{\lambda}{\lambda_{c}}\right)^{2}}}
$$

The ABCD matrices for Layer 1 and Layer 3 with known permittivity and permeability can be calculated. Therefore, the ABCD matrix for Layer 2 can be obtained by de-embedding:

$$
\left[\begin{array}{ll}
A_{2} & B_{2} \\
C_{2} & D_{2}
\end{array}\right]=\left[\begin{array}{ll}
A_{1} & B_{1} \\
C_{1} & D_{1}
\end{array}\right]^{-1}\left[\begin{array}{ll}
A & B \\
C & D
\end{array}\right]\left[\begin{array}{ll}
A_{3} & B_{3} \\
C_{3} & D_{3}
\end{array}\right]^{-1}
$$

In practice, the calculated $\mathrm{ABCD}$ matrix does not conform to Equation (7), so the permittivity could not be directly computed based on Equations (8-10). The ABCD matrix is further converted to S parameters:

$$
\begin{aligned}
& {\left[\begin{array}{ll}
\mathrm{A} & \mathrm{B} \\
\mathrm{C} & \mathrm{D}
\end{array}\right] \rightarrow\left[\begin{array}{ll}
\mathrm{S}_{11} & \mathrm{~S}_{12} \\
\mathrm{~S}_{21} & \mathrm{~S}_{22}
\end{array}\right]} \\
& \mathrm{S}_{11}=\frac{\mathrm{A}+\mathrm{B} / Z_{0}-\mathrm{C} Z_{0}-\mathrm{D}}{\mathrm{A}+\mathrm{B} / Z_{0}+\mathrm{C} Z_{0}+\mathrm{D}} \\
& \mathrm{S}_{12}=\frac{2(\mathrm{AD}-\mathrm{BC})}{\mathrm{A}+\mathrm{B} / Z_{0}+\mathrm{C} Z_{0}+\mathrm{D}} \\
& \mathrm{S}_{21}=\frac{2}{\mathrm{~A}+\mathrm{B} / Z_{0}+\mathrm{C} Z_{0}+\mathrm{D}} \\
& \mathrm{S}_{22}=\frac{-\mathrm{A}+\mathrm{B} / Z_{0}-\mathrm{C} Z_{0}+\mathrm{D}}{\mathrm{A}+\mathrm{B} / Z_{0}+\mathrm{C} Z_{0}+\mathrm{D}}
\end{aligned}
$$

The new S parameters can be viewed as the data measured at the reference planes shifted inwards to the interfaces between the sample and the windows. Two methods are available for use to extract the permittivity from the S parameters: the Nicolson-Ross-Weir (NRW) solution (Weir, 1974) and Tischer's model (Tischer, 1960). 


\subsubsection{Nicolson-Ross-Weir solution}

In the NRW algorithm the reflection coefficient $\Gamma$ is computed first from the $\mathrm{S}$ parameters:

$$
\Gamma=X \pm \sqrt{X^{2}-1}
$$

where

$$
X=\frac{\mathrm{S}_{11}^{2}-\mathrm{S}_{21}^{2}+1}{2 \mathrm{~S}_{11}}
$$

The correct root in Equation (13) is chosen by requiring $|\Gamma| \leq 1$. The transmission coefficient $T$ for the NRW solution is given by

$$
T=\frac{\mathrm{S}_{11}+\mathrm{S}_{21}-\Gamma}{1-\left(\mathrm{S}_{11}+\mathrm{S}_{21}\right) \Gamma}
$$

The relative magnetic permeability of the second layer $\mu_{\mathrm{r} 2}$ can be calculated by

$$
\mu_{\mathrm{r} 2}=\frac{\lambda_{g}(1+\Gamma)}{\Lambda(1-\Gamma)}
$$

where

$$
\frac{1}{\Lambda^{2}}=-\left[\frac{1}{2 \pi t_{2}} \ln \left(\frac{1}{T}\right)\right]^{2}
$$

Equation (17) has an infinite number of roots since the imaginary part of the logarithm of a complex number is equal to the angle of the complex value plus $2 \pi \mathrm{k}$, where $\mathrm{k}$ is equal to the integer of $\left(\mathrm{t}_{2} / \lambda_{\mathrm{g}}\right)$.

The permittivity $\varepsilon_{\mathrm{r} 2}$ is given by:

$$
\varepsilon_{\mathrm{r} 2}=\frac{\lambda^{2}}{\mu_{\mathrm{r} 2}}\left(\frac{1}{\lambda_{c}^{2}}+\frac{1}{\Lambda^{2}}\right)
$$


The NRW solution is not explicit due to the phase ambiguity. And spurious peaks would occur in the permittivity and permeability curves when the thickness of the sample is an integral multiple of a half wavelength of the microwaves within the sample (Kim et al., 2011).

\subsubsection{Tischer model}

For the materials with negligible magnetic permeability, the Tischer model can be used for permittivity calculation. Assuming there is only one layer with a thickness of $t_{0}$, the expressions for $\mathrm{S}_{11}$ and $\mathrm{S}_{21}$ are (Tischer, 1960):

$$
\begin{aligned}
& \mathrm{S}_{11}=\frac{-2\left(\gamma^{2}+\beta_{0}^{2}\right) \sinh \gamma t_{0}}{2\left(\gamma^{2}-\beta_{0}^{2}\right) \sinh \gamma t_{0}+4 j \gamma \beta_{0} \cosh \gamma t_{0}} \\
& \mathrm{~S}_{21}=\frac{4 j \gamma \beta_{0}}{2\left(\gamma^{2}-\beta_{0}^{2}\right) \sinh \gamma t_{0}+4 j \gamma \beta_{0} \cosh \gamma t_{0}}
\end{aligned}
$$

where $\beta_{0}=2 \pi / \lambda_{\mathrm{g}}$ is the phase constant of the transmission line. Here, the complex propagation constant $\gamma$ is given by

$$
\gamma=j 2 \pi \sqrt{\frac{\varepsilon_{\mathrm{r}}}{\lambda^{2}}-\frac{1}{\lambda_{c}^{2}}}
$$

The Newton-Raphson approximation method can be applied to solve the transcendental equations (Equations (22) and (23)) for the unknown $\gamma$ (Ball and Horsfield, 1998):

$$
\begin{aligned}
& S_{11}-\left[S_{11}\right]_{\text {meas }}=0 \\
& S_{21}-\left[S_{21}\right]_{\text {meas }}=0
\end{aligned}
$$

where $\left[\mathrm{S}_{11}\right]_{\text {meas }}$ and $\left[\mathrm{S}_{21}\right]_{\text {meas }}$ are measured reflection coefficient and transmission coefficient, respectively.

Then, the permittivity can be computed by

$$
\varepsilon_{r}=\lambda^{2}\left[\left(\frac{\gamma}{j 2 \pi}\right)^{2}+\frac{1}{\lambda_{c}^{2}}\right]
$$




\subsection{Musil-Zacek approach}

A closed form solution for this three-layer problem proposed by Musil and Zacek (Weir, 1974) is adopted here. In this approach, Layer 1 and Layer 3 should be identical, that is, $\varepsilon_{\mathrm{r} 1}=\varepsilon_{\mathrm{r} 3}, \mathrm{t}_{1}=\mathrm{t}_{3}$, and $\mu_{\mathrm{r} 1}=\mu_{\mathrm{r} 2}=\mu_{\mathrm{r} 3}=1$. The overall $\mathrm{S}_{11}$ of the three layers is written as (Haigh et al., 2001; Musil and Zacek, 1986):

$$
\mathrm{S}_{11}=\frac{a\left(c e^{2 \gamma_{1} t_{1}}+d\right) e^{2 \gamma_{2} t_{2}}+b\left(1+c d e^{2 \gamma_{1} t_{1}}\right)}{a\left(e^{2 \gamma_{1} t_{1}}+c d\right) e^{2 \gamma_{2} t_{2}}+b\left(c+d e^{2 \gamma_{1} t_{1}}\right)}
$$

where a, b, c and d are given by

$$
\begin{gathered}
a=\left(1+\frac{j \beta_{0}}{\gamma_{2}}\right) \cosh \left(\gamma_{1} t_{1}\right)+\left(\frac{j \beta_{0}}{\gamma_{1}}+\frac{\gamma_{1}}{\gamma_{2}}\right) \sinh \left(\gamma_{1} t_{1}\right) \\
b=\left(1-\frac{j \beta_{0}}{\gamma_{2}}\right) \cosh \left(\gamma_{1} t_{1}\right)+\left(\frac{j \beta_{0}}{\gamma_{1}}-\frac{\gamma_{1}}{\gamma_{2}}\right) \sinh \left(\gamma_{1} t_{1}\right) \\
c=\frac{j \beta_{0}-\gamma_{1}}{j \beta_{0}+\gamma_{1}} \\
d=\frac{\gamma_{1}-\gamma_{2}}{\gamma_{1}+\gamma_{2}}
\end{gathered}
$$

where $\gamma_{1}$ is the complex propagation constant of the first and third layers, and $\gamma_{2}$ is the complex propagation constant of the second layer. $\gamma_{1}$ and $\gamma_{2}$ can be computed based on Equation (21).

The overall $\mathrm{S}_{21}$ of the whole cell is derived as (Haigh et al., 2001):

$$
\begin{gathered}
\mathrm{S}_{21}=\left\{\cosh \left(\gamma_{2} t_{2}\right)\left[\cosh ^{2}\left(\gamma_{1} t_{1}\right)+\sinh ^{2}\left(\gamma_{1} t_{1}\right)+\frac{1}{2}\left(\frac{\gamma_{1}}{j \beta_{0}}+\frac{j \beta_{0}}{\gamma_{1}}\right) \sinh \left(2 \gamma_{1} t_{1}\right)\right]\right. \\
+\frac{1}{2} \sinh \left(\gamma_{2} t_{2}\right)\left[\left(\frac{\gamma_{1}}{\gamma_{2}}+\frac{\gamma_{2}}{\gamma_{1}}\right) \sinh \left(2 \gamma_{1} t_{1}\right)+\left(\frac{j \beta_{0}}{\gamma_{2}}+\frac{\gamma_{2}}{j \beta_{0}}\right) \cosh ^{2}\left(\gamma_{1} t_{1}\right)\right. \\
\left.\left.+\left(\frac{j \beta_{0} \gamma_{2}}{\gamma_{1}^{2}}+\frac{\gamma_{1}^{2}}{j \beta_{0} \gamma_{2}}\right) \sinh ^{2}\left(\gamma_{1} t_{1}\right)\right]\right\}^{-1}
\end{gathered}
$$


Similarly, the Newton-Raphson approximation method can be used to extract the permittivity from the expression of $\mathrm{S}_{11}$ or $\mathrm{S}_{21}$.

\subsection{Discussion}

The permittivity calculation procedure for the three-layer problem is summarised in Figure 3.

Different from the Musil-Zacek approach, in the CM method the windows are not limited to be of the same thickness and material. As a non-iterative method, the computational speed of the NRW solution is the fastest among the methods considered. And it can also be used for the calculation of permeability $\mu$, although this is not necessary here (water and honeys are nonmagnetic materials).

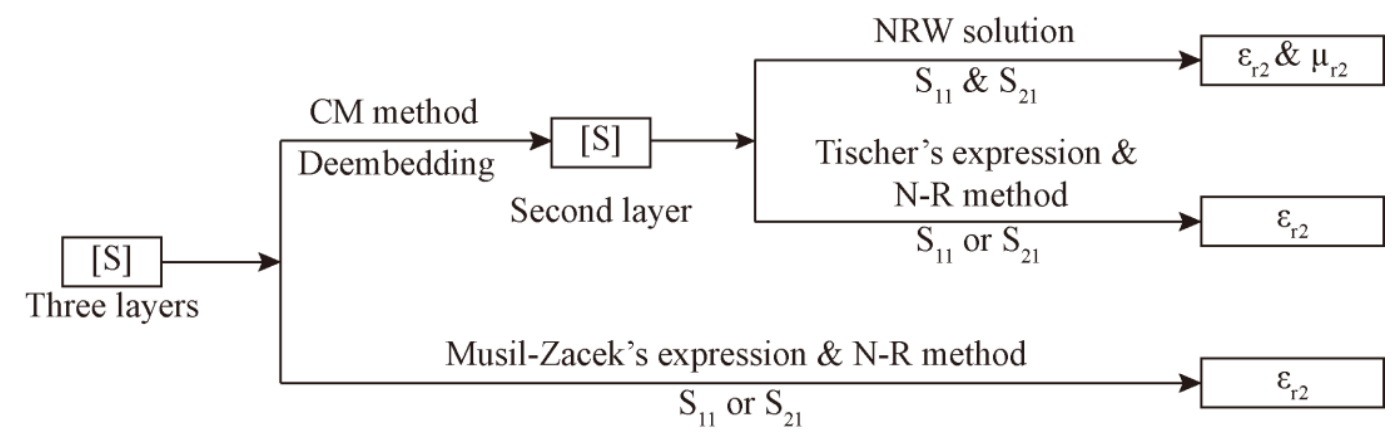

Figure 3 Permittivity calculation procedure for the three-layer problem of the liquid permittivity measurement

As mentioned above, in the NRW solution, the parameter k should be carefully chosen. For the Newton-Raphson approximation method, the differentiation of $S_{11}$ or $S_{21}$ with respect to the propagation constant $\gamma$ needs to be derived beforehand, and results depend on the initial estimation of the permittivity by trial and error. However, for intelligent algorithms (e.g., genetic algorithm (GA) (Mitchell, 1996), particle swarm optimisation and ant colony algorithm), the derivatives of the objective function and constraints are not required, and they have better global search abilities than traditional optimisation methods. Hence, the genetic algorithm can be introduced to obtain an approximate value of the permittivity, which can be used as a reference/starting point for more accurate calculation in the NRW and Newton-Raphson method. It is noted that the computation process of the GA is relatively time-consuming. Therefore, a compromise must be made between the 
accuracy and considerable computation time. In this work, the genetic algorithm with a relatively small population size and a few iterations is implemented.

The genetic algorithm simulates a natural genetics mechanism for synthetic systems based on operators that are duplicates of natural ones. The principle of survival of the fittest is applied into the optimisation, which consists of three primary genetic operators: selection, crossover and mutation. For the permittivity approximation, the fitness function as a measure of the quality of the solutions produced at each iteration is defined as follows:

$$
\mathrm{F}\left(\varepsilon_{\mathrm{GA}}\right)=\frac{1}{\frac{1}{\mathrm{~N}_{f}} \sum_{i=1}^{\mathrm{N}_{f}}\left|\frac{\mathrm{S}\left(\varepsilon_{\mathrm{GA}}, f_{i}\right)-\mathrm{S}_{\text {meas }}\left(f_{i}\right)}{\mathrm{S}_{\text {meas }}\left(f_{i}\right)}\right|+\delta}
$$

where $\mathrm{N}_{f}$ is the number of the frequency sampling points. $\varepsilon_{\mathrm{GA}}$ is a permittivity solution generated by the genetic algorithm. $\mathrm{S}$ can be either $\mathrm{S}_{11}$ (Equation (19) or Equation (25)) or $\mathrm{S}_{21}$ (Equation (20) or Equation (27)). $\delta$ is a small constant preset to avoid the singularity.

\section{Experimental setup}

The schematic diagram of the permittivity measurement using the transmission line technique is illustrated in Figure 4. A personal computer was connected to an HP8510C Vector Network Analyser (VNA) by an IEEE-488 cable. A MATLAB ${ }^{\circledR}$ programme was developed for acquisition of S-parameters from the VNA and permittivity computation. The output signal power level was set to $10.0 \mathrm{dBm}$ (i.e., $10 \mathrm{~mW})$. All the experiments were conducted at room temperature $\left(23 \pm 1^{\circ} \mathrm{C}\right)$. 


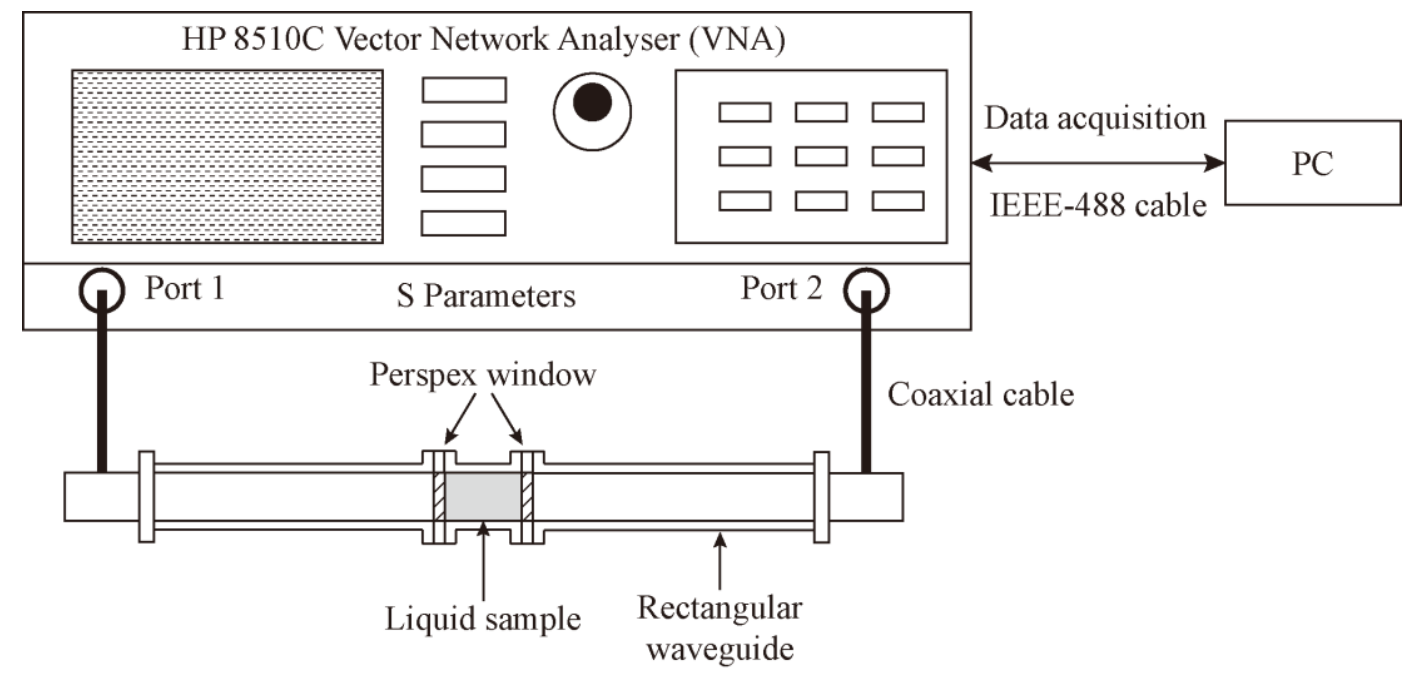

Figure 4 Setup of the transmission line technique for the permittivity measurement of liquids Two sets of rectangular waveguides were available for use. The thicknesses of the liquid layer and two Perspex windows $\left(\varepsilon_{\mathrm{r} 1}=\varepsilon_{\mathrm{r} 3}=2.6-j 0.06\right)$ for each set are listed in Table 2. It is seen that Musil-Zacek approach is applicable to the WG16 case. 201 frequency sampling points were chosen in both cases.

Table 2 Two sets of rectangular waveguides used in the test

\begin{tabular}{cccccc}
\hline & $\begin{array}{c}\text { Frequency } \\
\text { range }(\mathrm{GHz})\end{array}$ & $\begin{array}{c}\text { Inner dimensions of } \\
\text { waveguide cell }(\mathrm{mm})\end{array}$ & $\begin{array}{c}\text { Window 1 } \\
\left(\mathrm{t}_{1}, \mathrm{~mm}\right)\end{array}$ & $\begin{array}{c}\text { Sample layer } \\
\left(\mathrm{t}_{2}, \mathrm{~mm}\right)\end{array}$ & $\begin{array}{c}\text { Window 2 } \\
\left(\mathrm{t}_{3}, \mathrm{~mm}\right)\end{array}$ \\
\hline WG14 set & $6-8$ & $34.85 \times 15.80$ & 5.35 & 22.92 & 6.20 \\
\hline WG16 set & $8-12$ & $22.86 \times 10.16$ & 4.61 & 23.54 & 4.61 \\
\hline
\end{tabular}

Prior to the test, the VNA was calibrated using the thru-reflect-line (TRL) standard. Calibration accuracy was checked using a flush short. Over the frequency range attenuation was less than $0.1 \mathrm{~dB}$ and the phase shift was $180^{\circ} \pm 0.5^{\circ}$. The accuracy of each permittivity calculation method was verified by the measurement of air, where the empty sample cell was held by the two Perspex windows.

A bottle of clear honey and a bottle of set honey were purchased from a local supermarket. The balance of the fructose and glucose determines whether a honey is clear or set. The set honey is more viscous than the clear honey, as the fructose content in the latter honey is higher. However, there is 
no difference in the taste or nutritional value of these two types. The details of the nutrition are listed in Table 3. In the honey test, every liquid sample was carefully placed into the waveguide cell, making sure that no air bubbles were trapped inside.

Table 3 Composition of the honeys used in the test $(100 \mathrm{~g})$

\begin{tabular}{cccccc}
\hline Energy $(\mathrm{kJ})$ & Fat $(\mathrm{g})$ & Carbohydrate $(\mathrm{g})$ & Fibre $(\mathrm{g})$ & Protein $(\mathrm{g})$ & Salt $(\mathrm{g})$ \\
\hline 1386 & $<0.1$ & 81.0 & $<0.1$ & 0.5 & 0.1
\end{tabular}

\section{Experimental results}

\subsection{Permittivity of water}

In this test, distilled water was measured over 6-8 GHz. Its permittivity calculated by CM-NRW and CM-Tischer methods is shown in Figure 5.The empirical values given by the Cole-Cole equation (Equation (2)) at $20^{\circ} \mathrm{C}$ and $30^{\circ} \mathrm{C}$ are also presented for comparison. For $\varepsilon_{r}^{\prime}$, the errors of CM-NRW and CM-Tischer- $\mathrm{S}_{11}$ are about $7 \%$ and $13 \%$, respectively. Only the CM-Tischer- $\mathrm{S}_{21}$ curve is close to the two Cole-Cole curves. In terms of $\varepsilon^{\prime \prime} r$, all the three curves are between the Cole-Cole curves as expected, while the CM-Tischer- $\mathrm{S}_{11}$ curve is not as stable as the other two curves.

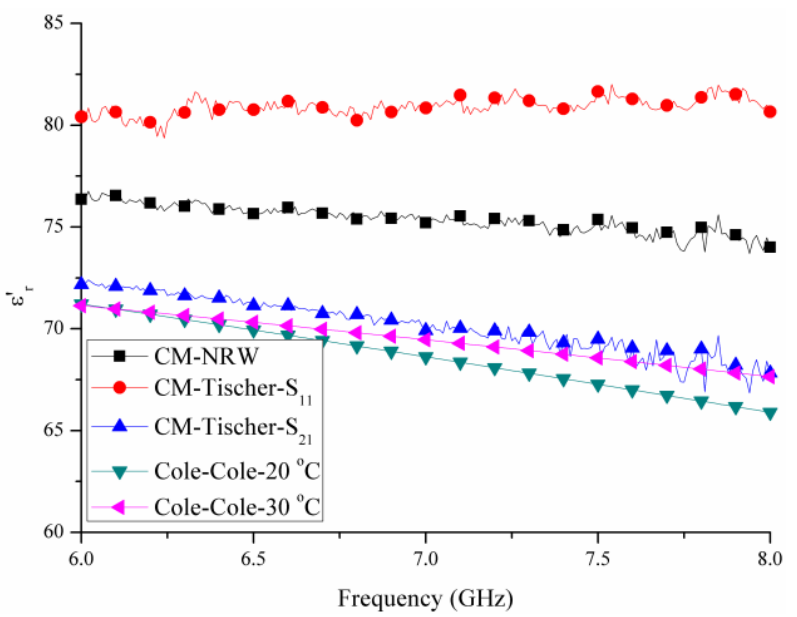

(a) $\varepsilon_{r}^{\prime}$

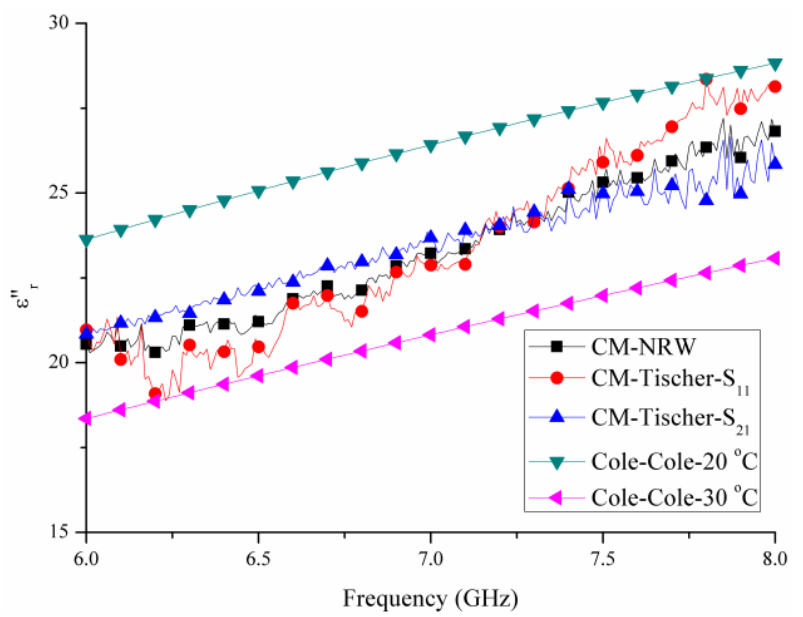

(b) $\varepsilon^{\prime \prime} r$

Figure 5 Relative permittivity of distilled water measured over WG14 (6-8 GHz)

The permittivity results of water provided by WG16 measurement are demonstrated in Figure 6. For $\varepsilon_{r}^{\prime}$, the CM-Tischer-S $\mathrm{S}_{11}$ and Musil-Zacek-S ${ }_{11}$ curves overlap, and both are above the Cole-Cole 
curves. There are many peaks in the CM-NRW curve, and most of the values beyond approximately 8.5 GHz are below the Cole-Cole curve at $20^{\circ} \mathrm{C}$. In Figure 6 (b), the CM-Tischer and Musil-Zacek methods produce the same imaginary permittivity, and only the curves at the frequency above around 10.5 GHz are within the Cole-Cole curves. Some instability exists in the CM-NRW curve as well.

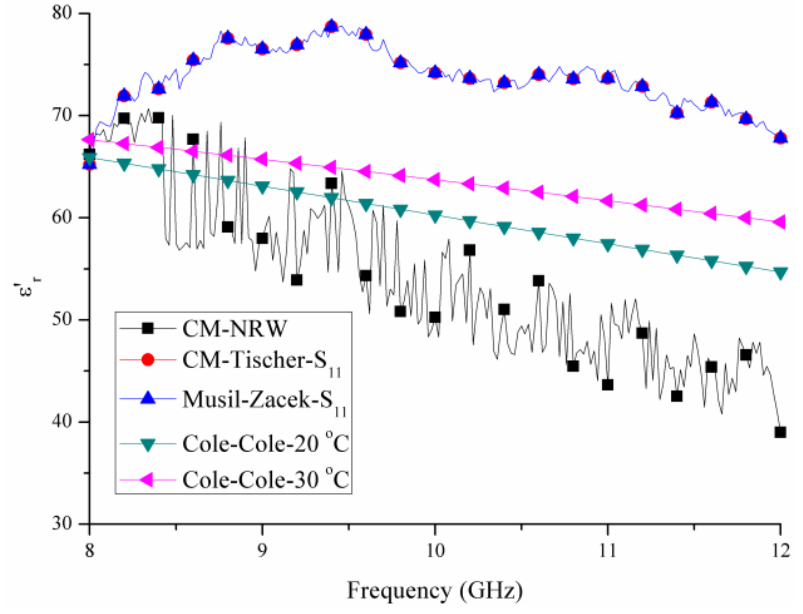

(a) $\varepsilon_{r}^{\prime}$

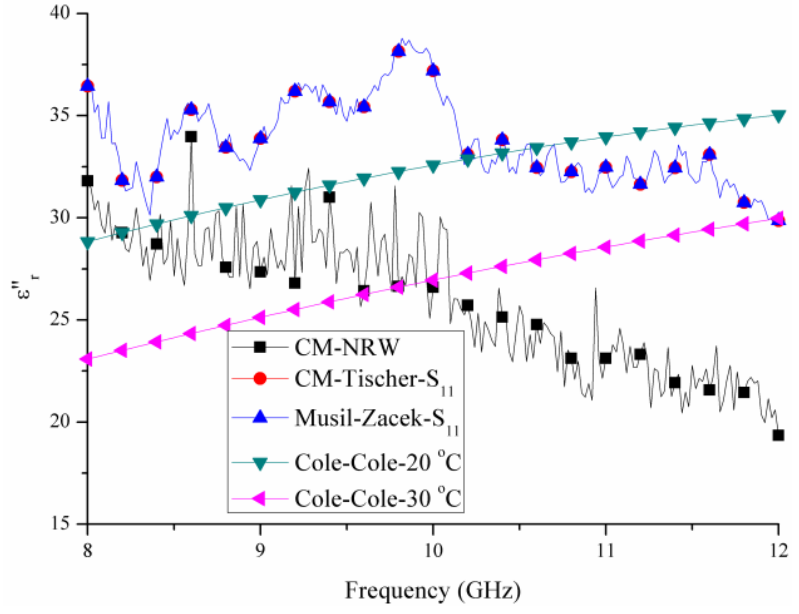

(b) $\varepsilon^{\prime \prime} r$

Figure 6 Relative permittivity of distilled water measured over WG16 (8-12 GHz)

It is worth mentioning that neither CM-Tischer method nor Musil-Zacek method could provide satisfactory permittivity from $\mathrm{S}_{21}$. The measured $\mathrm{S}_{21}$ values are presented in Figure 7 . The magnitude is well below $-60 \mathrm{~dB}$, which means less than $0.0001 \%$ of the input power is transmitted through the Perspex windows and the honey sample. In addition, the phase curve varies randomly suggesting poor penetration of the microwaves, which results in inaccurate permittivity calculation over this frequency band. 


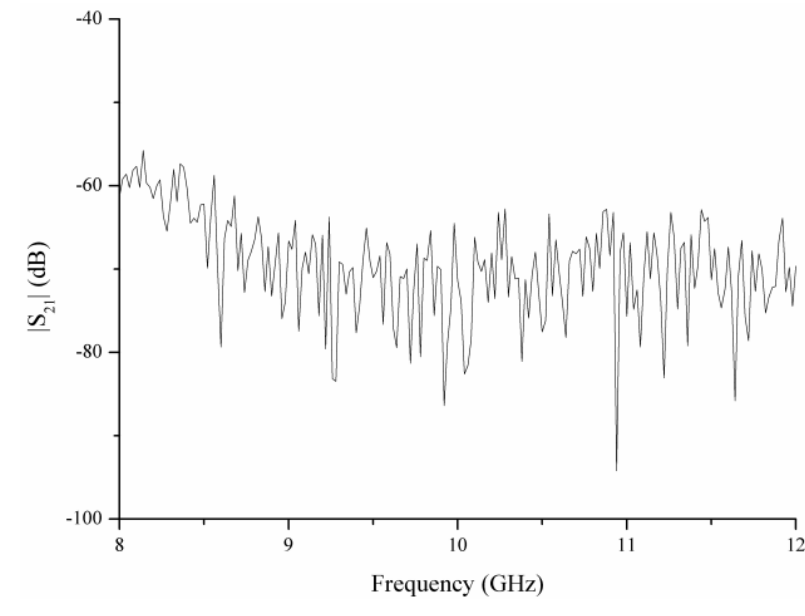

(a) Magnitude

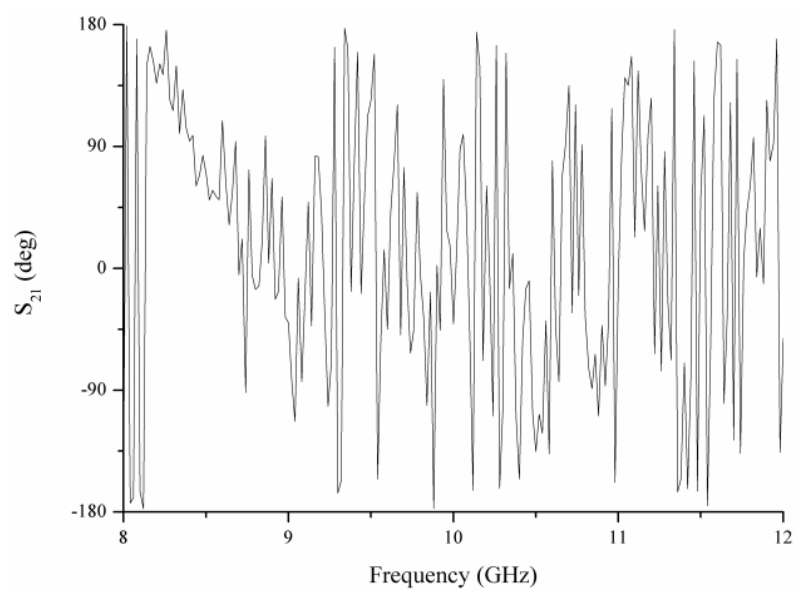

(b) Phase

Figure 7 Measured transmission coefficient $\mathrm{S}_{21}$ from the WG16 test of distilled water

From the measurements using the two waveguide sets, it is found that the Musil-Zacek method is equivalent to the CM-Tischer method. And the combination of WG14 and the CM-Tischer-S 21 method offers the best performance in terms of signal penetration and computational accuracy. Hence, this combination is selected in the following studies.

\subsection{Permittivity of clear honey}

Here the genetic algorithm is employed to find an approximate permittivity of the clear honey, as its permittivity was unknown before the test. The maximum permittivity of water (data given by the CM-Tischer-S $\mathrm{S}_{21}$ method) is set as the upper limit, while the permittivity of free space (1-j0) is the lower limit. Hence, the limits initialised in the optimisation are: $\varepsilon_{r}^{\prime}$ ranges from 1 to 72 and $\varepsilon^{\prime \prime}{ }_{r}$ ranges from 0 to 26. Main GA parameters used are listed in Table 4. Both the population size and number of iterations are set to 200, so the whole process can be performed within a short period. For a personal computer with an Intel core i5 Central Processing Unit (CPU), double processors and 4 GB memory, it took about 2.5 minutes to complete. 
Table 4 Main parameters of the genetic algorithm used for the clear honey's permittivity approximation

\begin{tabular}{ccccc}
\hline Population size & Number of iterations & Crossover rate & Mutation rate & $\delta$ \\
\hline 200 & 200 & $60 \%$ & $1 \%$ & 0.01
\end{tabular}

As plotted in Figure 8, after the optimisation process, most of the fitness values are near to 100 , which indicates that ideal solutions are achieved according to Equation (28). The permittivity at the frequencies where the fitness values are above 90 is averaged, and the average value $7.16-\mathrm{j} 2.71$ is set as the input estimation for the Newton-Raphson method. The resultant permittivity of the clear honey is shown in Figure 9.The final $\varepsilon_{r}^{\prime}$ and $\varepsilon^{\prime \prime}{ }_{r}$ are close to the average value by GA, which denotes high efficiency offered by the genetic optimisation for permittivity approximation.

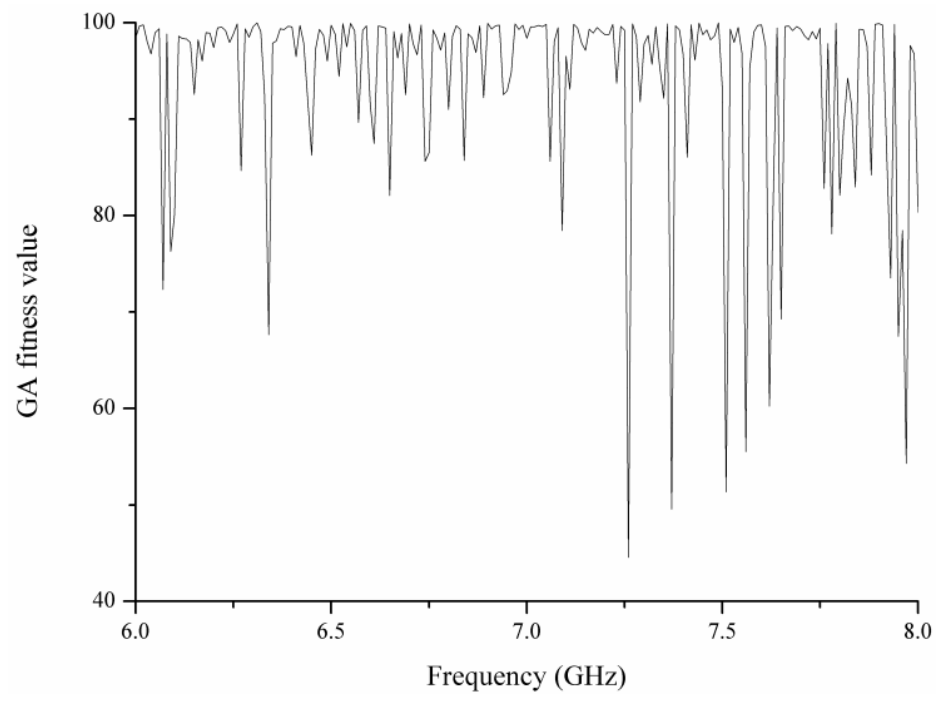

Figure 8 Best fitness value of GA at each frequency sampling point for the permittivity approximation of the clear honey 


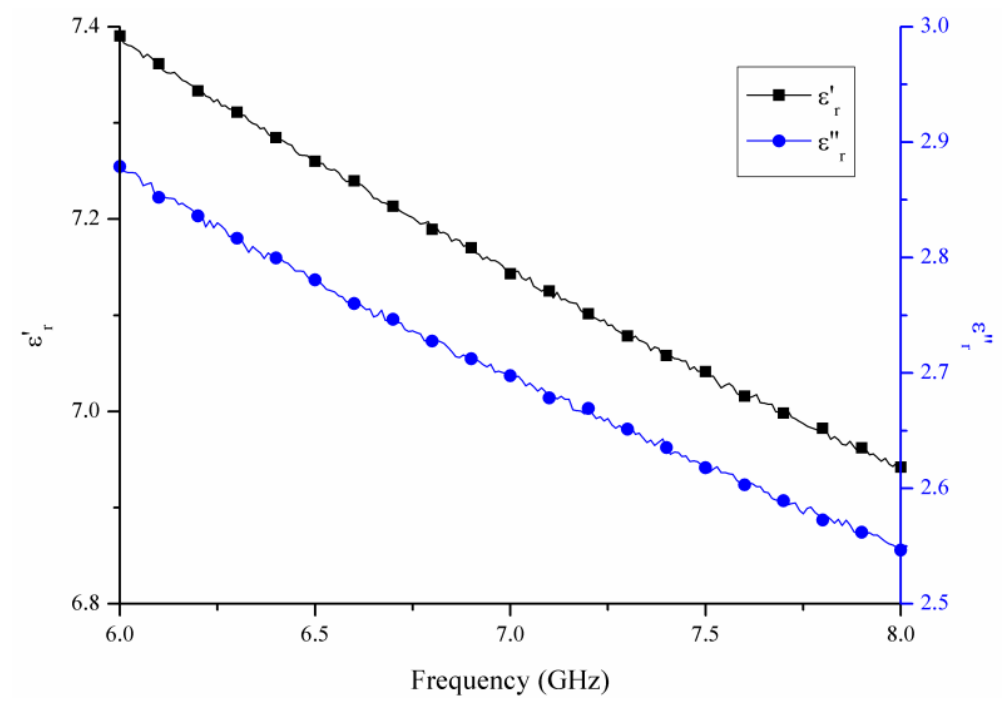

Figure 9 Permittivity of the clear honey provided by the WG 14 measurement

\subsection{Permittivity of set honey}

Same as the clear honey, the genetic algorithm is employed for initial permittivity approximation as well. The permittivity results of the set honey are presented in Figure 10. It is seen that both $\varepsilon_{r}^{\prime}$ and $\varepsilon^{\prime \prime}{ }_{r}$ are slightly smaller than those of the clear honey.

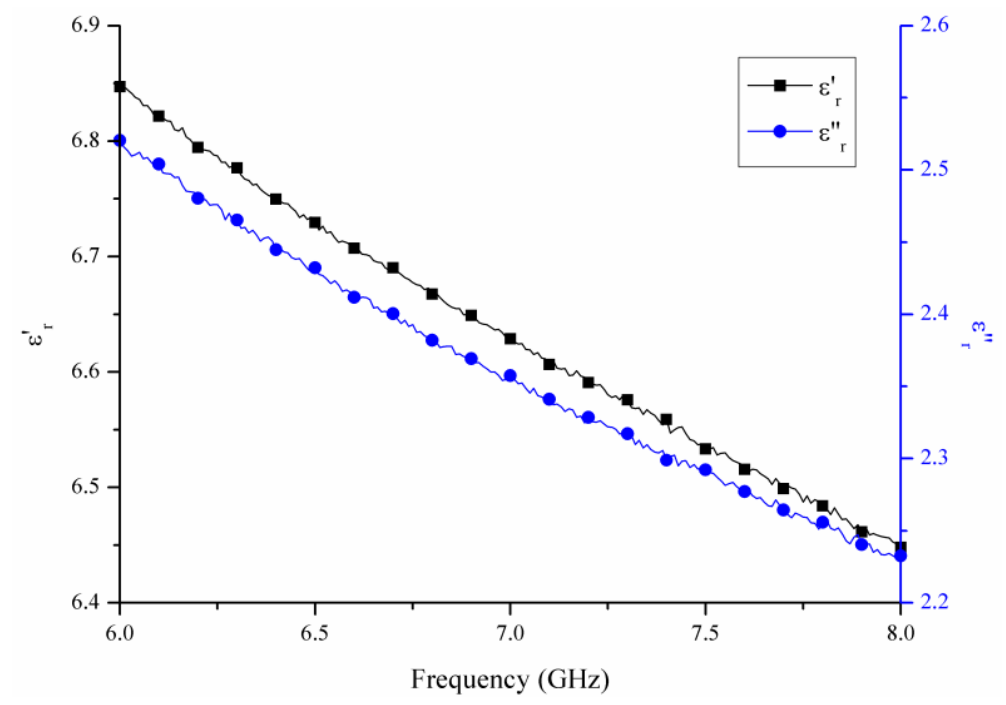

Figure 10 Permittivity of the set honey provided by WG 14 measurement

\subsection{Discussion}

(1) The effect of the calibration errors on the accuracy of the honey permittivity measurement is investigated. Four special cases with the magnitude and phase of all the four S-parameters added or 
subtracted by the calibration errors of attenuation (i.e., $\pm 0.1 \mathrm{~dB}$ ) and phase shift (i.e., $\pm 0.5^{\circ}$ ) are considered. By comparing the permittivity differences between the four cases, the measurement uncertainties can be obtained. The measurement uncertainties at five frequencies are presented in Table 5 .

Table 5 The relative permittivity of the clear and set honeys with the measurement uncertainties

\begin{tabular}{ccccccc}
\hline & & $6 \mathrm{GHz}$ & $6.5 \mathrm{GHz}$ & $7 \mathrm{GHz}$ & $7.5 \mathrm{GHz}$ & $8 \mathrm{GHz}$ \\
\hline \multirow{3}{*}{ Clear honey } & $\varepsilon_{r}^{\prime}$ & $7.39 \pm 0.03$ & $7.26 \pm 0.02$ & $7.14 \pm 0.02$ & $7.04 \pm 0.02$ & $6.94 \pm 0.01$ \\
& $\varepsilon_{r}^{\prime \prime}$ & $2.88 \pm 0.03$ & $2.78 \pm 0.02$ & $2.70 \pm 0.02$ & $2.62 \pm 0.02$ & $2.55 \pm 0.02$ \\
& $\varepsilon_{r}^{\prime}$ & $6.85 \pm 0.02$ & $6.73 \pm 0.02$ & $6.63 \pm 0.02$ & $6.54 \pm 0.02$ & $6.45 \pm 0.01$ \\
Set honey & & & & & & \\
& $\varepsilon_{r}^{\prime \prime}$ & $2.52 \pm 0.03$ & $2.43 \pm 0.02$ & $2.36 \pm 0.02$ & $2.29 \pm 0.02$ & $2.23 \pm 0.02$
\end{tabular}

(2) The genetic algorithm is also applied to acquire the Cole-Cole parameters for the honeys under test. According to Equation (2), four Cole-Cole variables (i.e., $\varepsilon_{\mathrm{s}}, \varepsilon_{\infty}, \tau$ and $\alpha$ ) are involved in this optimisation. Here another fitness function for evaluation is defined:

$$
\mathrm{F}^{\prime}\left(\varepsilon_{\mathrm{s}}, \varepsilon_{\infty}, \tau, \alpha\right)=\frac{1}{\frac{1}{\mathrm{~N}_{f}} \sum_{i=1}^{\mathrm{N}_{f}}\left|\frac{\varepsilon_{r}\left(\varepsilon_{\mathrm{s}}, \varepsilon_{\infty}, \tau, \alpha, f_{i}\right)-\varepsilon_{\text {meas }}\left(f_{i}\right)}{\varepsilon_{\text {meas }}\left(f_{i}\right)}\right|+\delta}
$$

The parameter settings of the GA are the same as those for permittivity approximation (Table 4). The calculated Cole-Cole parameters for the two types of honeys at room temperature and over 6-8 GHz are listed in Table 6. For each case, the computation can be finished within five seconds. In addition, a high fitness function value is achieved, which indicates good agreement with the measured permittivity. 
Table 6 Cole-Cole parameters for the clear and set honeys calculated by GA at room temperature and over $6-8 \mathrm{GHz}$

\begin{tabular}{cccccc}
\hline & $\varepsilon_{\mathrm{s}}$ & $\varepsilon_{\infty}$ & $\tau\left(10^{-11} \mathrm{~s}\right)$ & $\alpha$ & Fitness function value \\
\hline Clear honey & 38.48 & 4.04 & 122.96 & 0.49 & 95.82 \\
& & & & & \\
\hline Set honey & 29.80 & 3.99 & 80.20 & 0.47 & 95.19
\end{tabular}

(3) An Agilent ${ }^{\bar{B}} 85070 \mathrm{E}$ 'Performance' dielectric probe was used to measure the complex permittivity of honey as well. The calibration was performed with air, a short circuit and distilled water. The tip of the probe was placed in the honey with no air bubbles between honey and the probe tip. The permittivity was calculated by the Agilent dielectric probe kit software after data acquisition of $\mathrm{S}_{11}$ from an HP8510A VNA.

The permittivity comparison between the transmission line technique (T-series) and the dielectric probe technique (D-series) is presented in Figure 11. In general, for each type of honey, the values obtained by the dielectric probe are lower than those by the transmission line technique. An example of the measurement difference at the centre frequency $7 \mathrm{GHz}$ is presented in Table 7 . The average differences of $\varepsilon_{r}^{\prime}$ and $\varepsilon^{\prime \prime}{ }_{r}$ are approximately $4 \%$ and $33 \%$.

There are some special characteristics about the dielectric probe used. For example, the material under test is assumed "infinite" in size, and the method is not recommended for low loss $(\tan \delta<0.5)$ materials with $\varepsilon_{r}^{\prime}>5$. The accuracy provided by the dielectric probe is $\varepsilon_{r}^{\prime}=\varepsilon_{r}^{\prime} \pm 0.05\left|\varepsilon_{r}\right|$ and $\varepsilon^{\prime \prime}{ }_{r}$ $=\varepsilon^{\prime \prime}{ }_{r} \pm 0.05\left|\varepsilon_{r}\right|$ (Agilent 85070E Dielectric Probe Kit $200 \mathrm{MHz}$ to $50 \mathrm{GHz}$ Technical Overview, 2012). For the present case, the honey samples belong to the low-loss materials that are not recommended for the measurement, which could be the reason of the measurement inaccuracy. Hence, the transmission line technique is more reliable for the permittivity measurement of the honey investigated. 


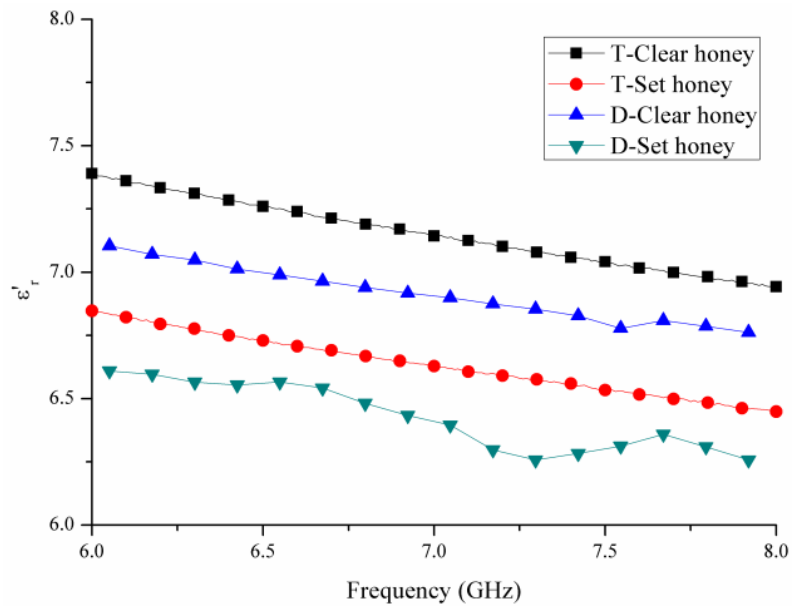

(a) $\varepsilon_{r}^{\prime}$

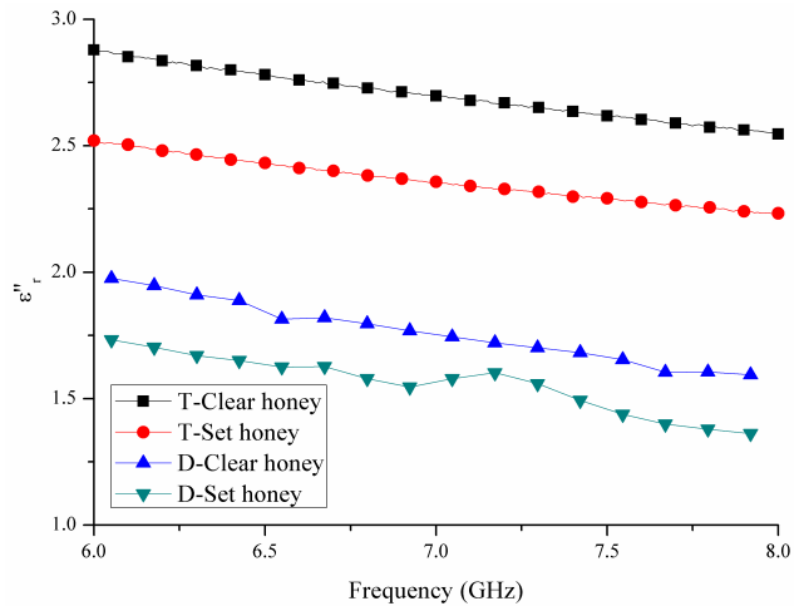

(b) $\varepsilon^{\prime \prime} r$

Figure 11 Comparison of the permittivity results obtained by the transmission line technique (Tseries) and the dielectric probe technique (D-series)

Table 7 Measured permittivity difference between the transmission line technique and the dielectric probe technique at $7 \mathrm{GHz}$

\begin{tabular}{ccccc}
\hline & $\varepsilon_{r}^{\prime}$-Clear honey & $\varepsilon_{r}^{\prime}$-Set honey & $\varepsilon^{\prime \prime}{ }_{r}$-Clear honey & $\varepsilon^{\prime \prime}{ }_{r}$-Set honey \\
\hline Transmission line technique & 7.1433 & 6.6288 & 2.6976 & 2.3575 \\
Dielectric probe technique & 6.8993 & 6.3950 & 1.7439 & 1.5786 \\
Difference (\%) & 3.42 & 3.53 & 35.35 & 33.04
\end{tabular}

(4) The effect of added water content on the permittivity is studied. For each type of honey, five tests with different added water amounts (i.e., $10 \mathrm{wt} \%, 20 \mathrm{wt} \%, 30 \mathrm{wt} \%, 40 \mathrm{wt} \%$ and $50 \mathrm{wt} \%$ ) were conducted. The masses of water and honey were accurately measured by a Precisa ${ }^{\circledR}$ XB $120 \mathrm{~A}$ electronic balance with precision of $0.0001 \mathrm{~g}$. The water and honey were mixed evenly. The permittivity values of the adulterated clear honeys with various added water contents are shown in Figure 12. Both $\varepsilon_{r}^{\prime}$ and $\varepsilon^{\prime \prime}{ }_{r}$ increase when more water is added. Curves of the cases with $40 \%$ and $50 \%$ added water become unstable at higher frequencies, which is similar to the trend of the curves of distilled water. It is noted that in the case with $50 \%$ added water $\varepsilon_{r}^{\prime}$ is approximately a half of that 
of water as expected. However, $\varepsilon^{\prime \prime}{ }_{r}$ of the clear honey-water mixture is near to that of water, which demonstrates that water has a significant effect on the dielectric loss of the mixture.

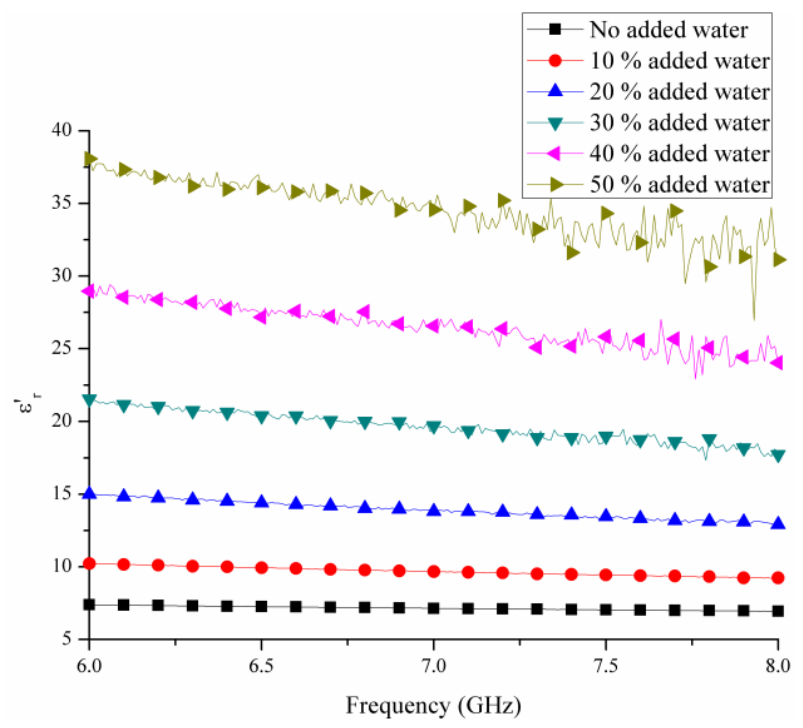

(a) $\varepsilon_{r}^{\prime}$

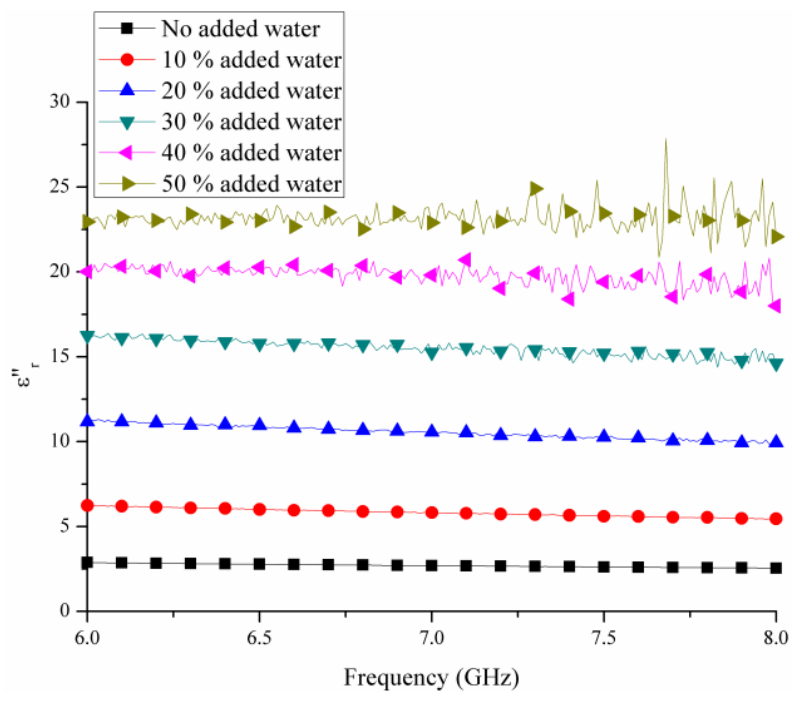

(b) $\varepsilon^{\prime \prime} r$

Figure 12 Effect of added water content on the permittivity of the adulterated clear honey

The effect of added water on the permittivity of the adulterated set honey is presented in Figure 13.

Similar variations due to the added water are observed. At the same added water content and frequency, both $\varepsilon_{r}^{\prime}$ and $\varepsilon^{\prime \prime}{ }_{r}$ of the adulterated set honey are slightly smaller than those of the adulterated clear honey as well.
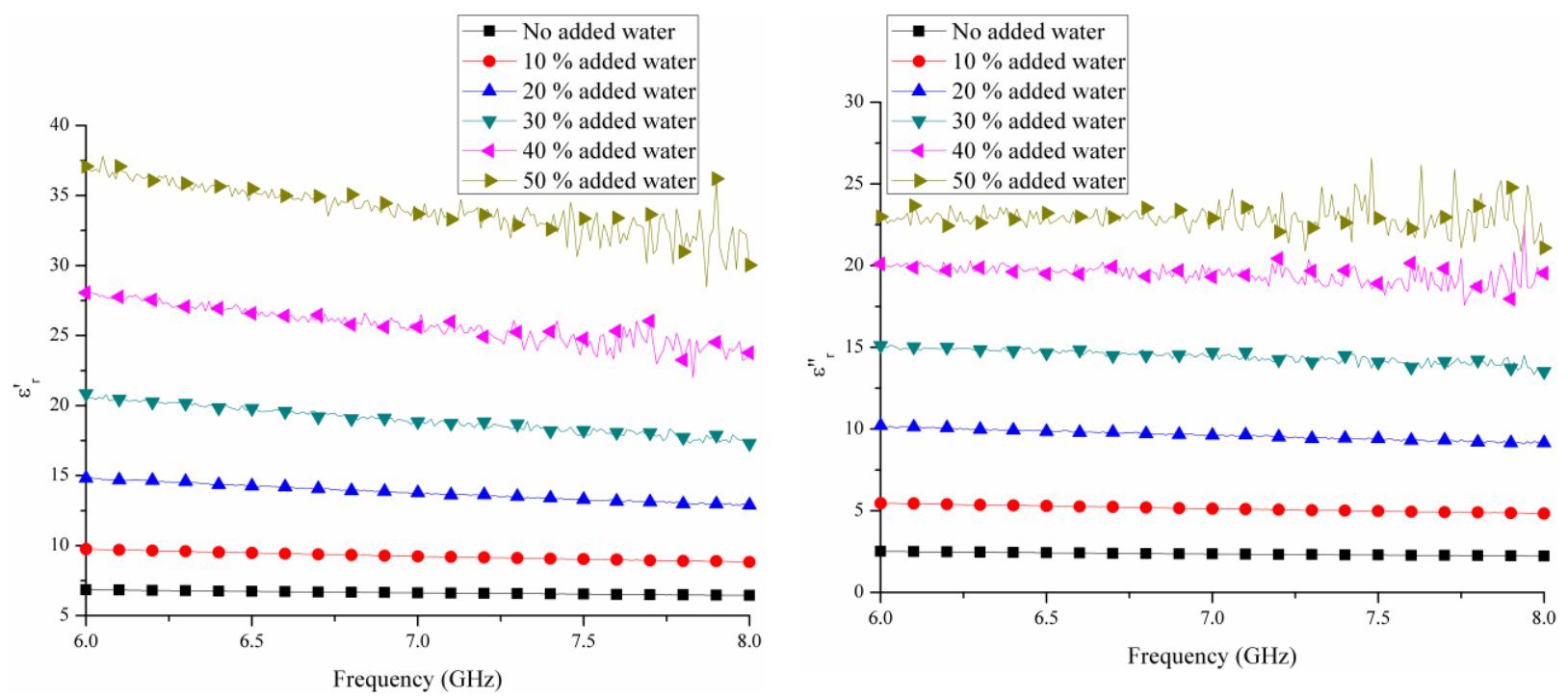

(a) $\varepsilon_{r}^{\prime}$
(b) $\varepsilon^{\prime \prime}{ }_{r}$

Figure 13 Effect of added water content on the permittivity of the adulterated set honey The relationship between the added water content and the relative permittivity of the honey-water mixture at the centre frequency is revealed in Figure 14. The permittivity results obtained can be fitted by regression to equations of the following form:

$$
\begin{aligned}
& \varepsilon_{\mathrm{r}}^{\prime}=\mathrm{m}_{2} \xi^{2}+\mathrm{m}_{1} \xi+\mathrm{m}_{0} \\
& \varepsilon_{\mathrm{r}}^{\prime \prime}=\mathrm{n}_{1} \xi+\mathrm{n}_{0}
\end{aligned}
$$

where $\xi$ is the weight percent of added water in the honey-water mixture.

The corresponding statistical regression coefficients and reliability of the approximation $\left(\mathrm{R}^{2}\right)$ are given in Table 8 . The high coefficients of determination indicate a strong correlation between the dielectric properties and the added water content. Considering the measurement uncertainty, the minimum weight percent of added water can be determined $(0.8 \%$ for the present two honey cases).

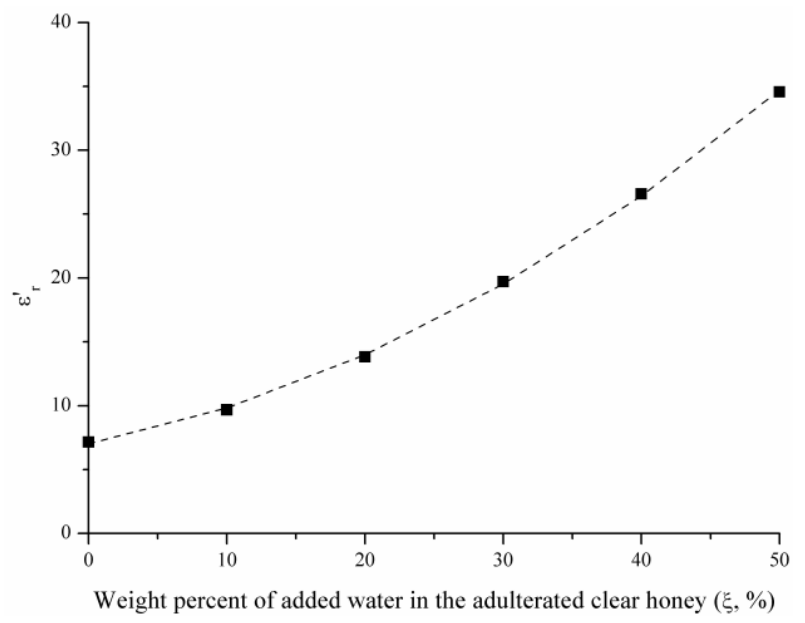

(a) $\varepsilon_{r}^{\prime}$-Clear honey

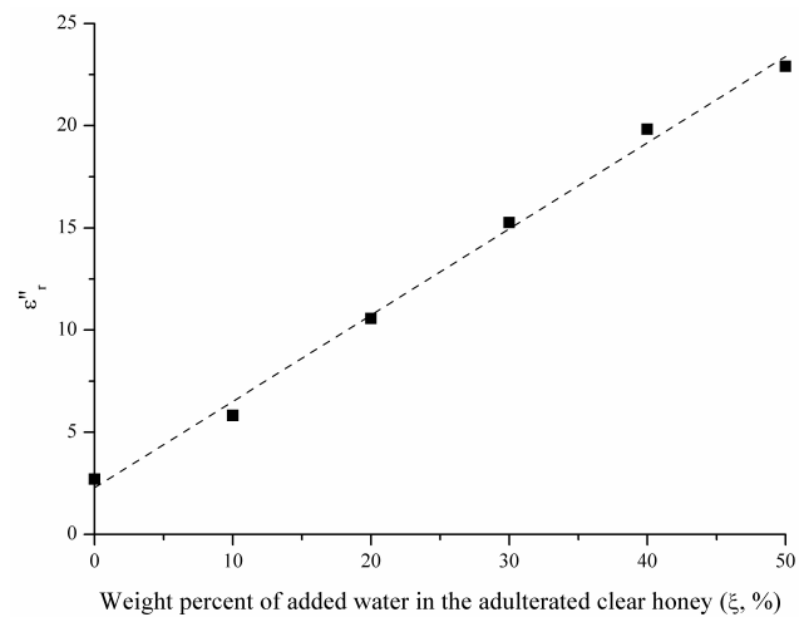

(b) $\varepsilon^{\prime \prime}{ }_{r}$-Clear honey 


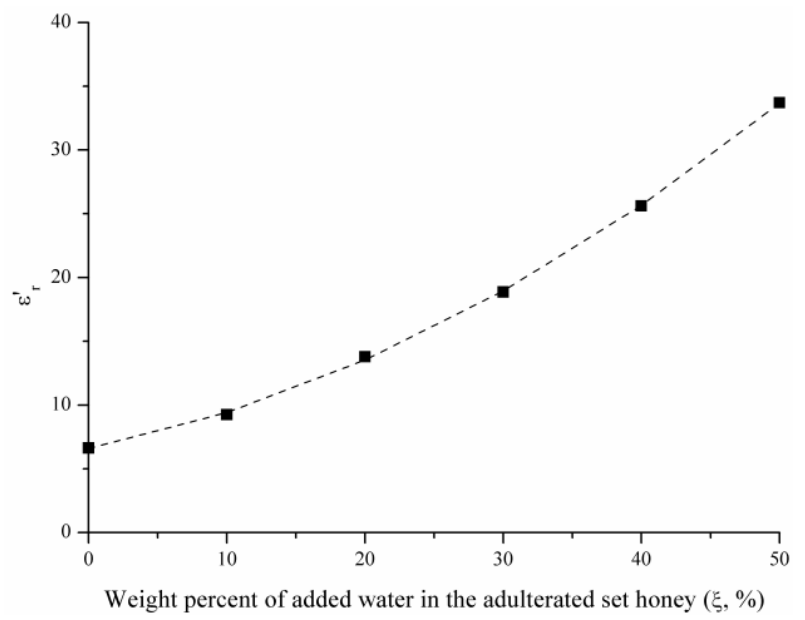

(c) $\varepsilon_{r}^{\prime}$ - Set honey

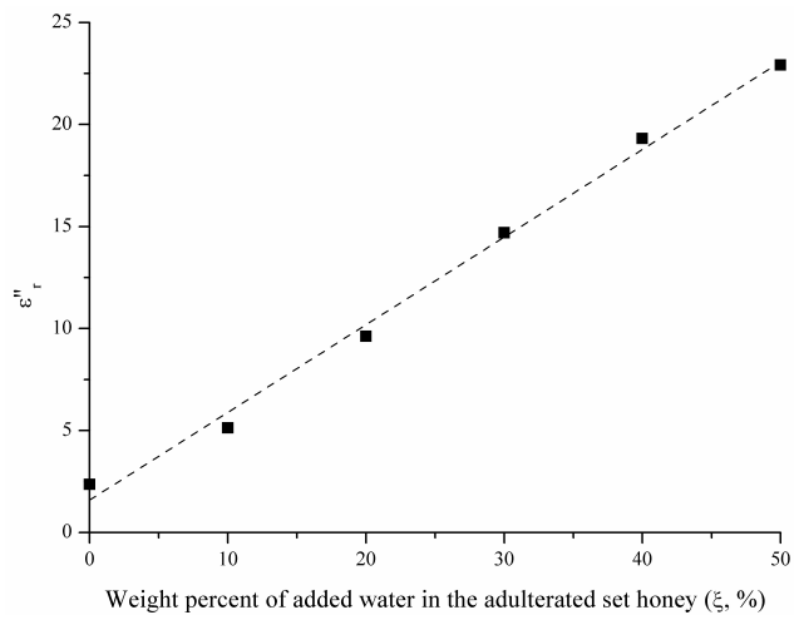

(d) $\varepsilon^{\prime \prime}$ - Set honey

Figure 14 Calibration curves showing relationship of $\varepsilon_{r}^{\prime}$ and $\varepsilon^{\prime \prime}{ }_{r}$ with added water content at $7 \mathrm{GHz}$ for clear and set honeys

Table 8 Regression statistics corresponding to Equations (30) and (31) for added water content approximation at room temperature $\left(23 \pm 1^{\circ} \mathrm{C}\right)$

\begin{tabular}{cccccccc}
\hline & $\mathrm{m}_{2}$ & $\mathrm{~m}_{1}$ & $\mathrm{~m}_{0}$ & $\mathrm{n}_{1}$ & $\mathrm{n}_{0}$ & $\mathrm{R}^{2}\left(\varepsilon_{r}^{\prime}\right)$ & $\mathrm{R}^{2}\left(\varepsilon_{r}^{\prime \prime}\right)$ \\
\hline Clear honey & 68.32 & 21.19 & 7.02 & 42.20 & 2.29 & 0.9998 & 0.9955 \\
\hline Set honey & 64.76 & 21.78 & 6.58 & 42.97 & 1.59 & 0.9998 & 0.9943 \\
\hline
\end{tabular}

\section{Concluding remarks}

The potential of the microwave transmission line technique for evaluation of honey purity has been presented. The permittivity can be used as a honey purity indicator. Two calculation methods (i.e., characteristic matrix method and Musil-Zacek approach) for the liquid permittivity measurement have been addressed. In the characteristic matrix method, the NRW solution and Tischer's model can be applied after de-embedding. The Musil-Zacek approach is only suited to the cases where the two windows are identical. From the measurement of distilled water, it has been found that the MusilZacek approach provides the same results as the characteristic matrix-Tischer method. Signal 
penetration is weak in the measurement over WG16 (8-12 GHz). By using the WG14 (6-8 GHz) waveguide set and the characteristic matrix-Tischer permittivity calculation methodology, the results obtained agree well with the empirical values given by the Cole-Cole equation.

Permittivity of the clear honey and set honey was measured over 6-8 GHz. The genetic algorithm has been employed to provide a reasonable permittivity value. The permittivity of the set honey is slightly smaller than that of the clear honey. In both cases, the permittivity decreases with increasing frequency. From the study of the measurement uncertainty, it has been shown that high accuracy of permittivity calculation can be achieved. The Cole-Cole parameters for the two types of honeys have been obtained using the genetic algorithm. A commercial dielectric coaxial probe was used for comparison, while some measurement inaccuracy is found due to the inherent limitations. Hence, the transmission line method is more suitable for the measurement of the honey samples studied.

Water was added into the honey samples to simulate the adulteration. The permittivity results of the adulterated honeys have shown that water has a significant effect. Specifically, the real permittivity $\varepsilon_{r}^{\prime}$ increases with the increased added water content, which roughly obeys the rule of mixture. However, a greater increase is observed in the imaginary permittivity $\varepsilon^{\prime \prime}{ }_{r}$. For the honey-water mixture with $50 \mathrm{wt} \%$ added water, $\varepsilon^{\prime \prime}{ }_{r}$ is close to that of water. From the regression analysis, relationships between the added water content and the permittivity of the adulterated honeys (i.e., a quadratic fit to $\varepsilon_{r}^{\prime}$ and a linear fit to $\varepsilon^{\prime \prime}{ }_{r}$ ) have been established with high reliability of approximation $\left(\mathrm{R}^{2}>0.994\right)$, which is convenient for a rapid and simple examination.

The microwave method demonstrated here can effectively measure the added water content in honeys, but further development is needed for practical industrial environments.

\section{Acknowledgements}

This work was financially supported by Dean's Doctoral Scholar Award of School of Materials, The University of Manchester. The first author gratefully acknowledges Paul Shaw and Daniel Vale from 
School of Electrical and Electronic Engineering for the assistance in the experiments. Special thanks to Professor Paulo Bartolo and Dr.Carl Diver for their advice and many useful discussions.

\section{References}

Agilent 85070E Dielectric Probe Kit $200 \mathrm{MHz}$ to $50 \mathrm{GHz}$ Technical Overview, 2012. . Santa Clara, CA, USA. Baginski, M.E., Faircloth, D.L., Deshpande, M.D., 2005. Comparison of two optimization techniques for the estimation of complex permittivities of multilayered structures using waveguide measurements. IEEE Trans. Microw. Theory Tech. 53, 3251-3259. doi:10.1109/TMTT.2005.855133

Ball, J.A.R., Horsfield, B., 1998. Resolving ambiguity in broadband waveguide permittivity measurements on moist materials. IEEE Trans. Instrum. Meas. 47, 390-392. doi:10.1109/19.744179

Bázár, G., Romvári, R., Szabó, A., Somogyi, T., Éles, V., Tsenkova, R., 2016. NIR detection of honey adulteration reveals differences in water spectral pattern. Food Chem. 194, 873-880. doi:10.1016/j.foodchem.2015.08.092

Chen, L., Xue, X., Ye, Z., Zhou, J., Chen, F., Zhao, J., 2011. Determination of Chinese honey adulterated with high fructose corn syrup by near infrared spectroscopy. Food Chem. 128, 1110-1114. doi:10.1016/j.foodchem.2010.10.027

Chua, H.S., Parkinson, G., Haigh, A.D., Gibson, A.A.P., 2007. A method of determining the moisture content of bulk wheat grain. J. Food Eng. 78, 1155-1158.

Gibson, A.A.P., Ng, S.K., Noh, B.B.M., Chua, H.S., Haigh, A.D., Parkinson, G., Ainsworth, P., Plunkett, A., 2008. An overview of microwave techniques for the efficient measurement of food materials. Food Manuf. Effic. 2, 1-9.

Guo, W., Zhu, X., Liu, Y., Zhuang, H., 2010. Sugar and water contents of honey with dielectric property sensing. J. Food Eng. 97, 275-281. doi:10.1016/j.jfoodeng.2009.10.024

Haigh, A.D., Thompson, F., Gibson, A.A.P., Campbell, G.M., Fang, C., 2001. Complex permittivity of liquid and granular materials using waveguide cells. Subsurf. Sens. Technol. Appl. 2, 425-434. 
doi:10.1023/A:1013273102533

Hasted, J.B., 1973. Aqueous dielectrics. Chapman \& Hall, London.

Jose, K.A., Varadan, V.K., Varadan, V. V., 2001. Wideband and noncontact characterization of the complex permittivity of liquids. Microw. Opt. Technol. Lett. 30, 75-79. doi:10.1002/mop.1225

Karpisz, T., Kopyt, P., Salski, B., Krupka, J., 2016. Open-ended waveguide measurement of liquids at millimeter wavelengths, in: 2016 IEEE MTT-S International Microwave Symposium (IMS). IEEE, pp. 1-4. doi:10.1109/MWSYM.2016.7539954

Kharkovsky, S., Zoughi, R., 2007. Microwave and millimeter wave nondestructive testing and evaluation Overview and recent advances. IEEE Instrum. Meas. Mag. 10, 26-38. doi:10.1109/MIM.2007.364985

Kim, S., Kuester, E.F., Holloway, C.L., Scher, A.D., Baker-Jarvis, J., 2011. Boundary effects on the determination of metamaterial parameters from normal incidence reflection and transmission measurements. IEEE Trans. Antennas Propag. 59, 2226-2240. doi:10.1109/TAP.2011.2143679

Kraszewski, A.W., Nelson, S.O., 1992. Observations on resonant cavity perturbation by dielectric objects. IEEE Trans. Microw. Theory Tech. 40, 151-155. doi:10.1109/22.108334

Li, Z., Haigh, A., Soutis, C., Gibson, A., Sloan, R., 2017. Microwaves Sensor for Wind Turbine Blade Inspection. Appl. Compos. Mater. 24, 495-512. doi:10.1007/s10443-016-9545-9

Liao, X., Raghavan, V.G., Meda, V., Yaylayan, V.A., 2001. Dielectric properties of supersaturated alpha-Dglucose aqueous solutions at $2450 \mathrm{MHz}$. J. Microw. Power Electromagn. Energy 36, 131-8. doi:10.1080/08327823.2001.11688455

Mitchell, M., 1996. An introduction to genetic algorithms. MIT Press.

Musil, J., Zacek, F., 1986. Microwave measurements of complex permittivity by free space methods and their applications. Elsevier Science Publishers, New York.

National Honey Board, 2003. Definition of honey and honey products.

Pozar, D., 2011. Microwave engineering, Fourth edi. ed. John Wiley \& Sons, New York. 
Puranik, S., Kumbharkhane, A., Mehrotra, S., 1991. Dielectric properties of honey-water mixtures between 10 MHz to $10 \mathrm{GHz}$ using time domain technique. J. Microw. Power Electromagn. Energy 26, 196-201. doi:10.1080/08327823.1991.11688157

Rulf, B., 1988. Transmission of microwaves through layered dielectrics-Theory, experiment, and application. Am. J. Phys. 56, 76. doi:10.1119/1.15436

Tischer, F.J., 1960. Measurement of the wave-propagation properties of plasma in the microwave region. IRE Trans. Instrum. I-9, 167-171. doi:10.1109/IRE-I.1960.5006909

Venkatesh, M.S., Raghavan, G.S. V, 2005. An overview of dielectric properties measuring techniques. Can. Biosyst. Eng. / Le Genie des Biosyst. au Canada 47, 15-30. doi:10.1109/URSIGASS.2011.6050287

Watts, C., Hanham, S.M., Ahmad, M.M., Adabi, M., Klein, N., 2016. Coupled dielectric-split ring microwave resonator for liquid measurements in microfluidic channels at nanoliter volumes, in: 46th European Microwave Conference. pp. 257-260.

Weir, W.B., 1974. Automatic measurement of complex dielectric constant and permeability at microwave frequencies. Proc. IEEE 62, 33-36. doi:10.1109/PROC.1974.9382 